\title{
Inhibition Performance of Chitosan-graft-Polyacrylamide as Environmentally Friendly and High-Cloud-Point Inhibitor on Nucleation and Growth of Methane Hydrate
}

Abdolreza Farhadian, ${ }^{\mathrm{a}, \mathrm{b}, \mathrm{c}}$ Mikhail A. Varfolomeev, ${ }^{\mathrm{a}, \mathrm{b},{ }^{*}}$ Alireza Shaabani, ${ }^{\mathrm{d}}$ Yulia F. Zaripova, ${ }^{\mathrm{b}}$ Vladimir V. Yarkovoi, ${ }^{b}$ Khasan R. Khayarov ${ }^{\mathrm{e}}$

aDepartment of Petroleum Engineering, Kazan Federal University, Kremlevskaya str. 18, 420008

Kazan, Russian Federation

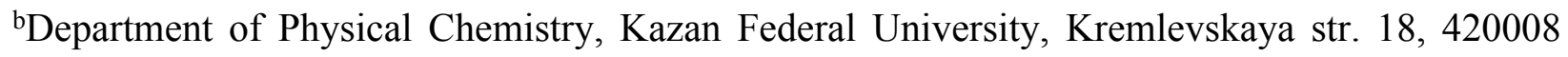

Kazan, Russian Federation

'Research Center for Oil and Gas Exploration, Shahid Beheshti University, GC, 1983969411, Tehran, Iran

dDepartment of Polymer \& Materials Chemistry, Faculty of Chemistry and Petroleum Science, Shahid Beheshti University, GC, 1983969411, Tehran, Iran

eInstitute of Chemistry, Kazan Federal University, Kremlevskaya str. 18, 420008 Kazan, Russian Federation

*Corresponding Author E-mail address: mikhail.varfolomeev@kpfu.ru. 


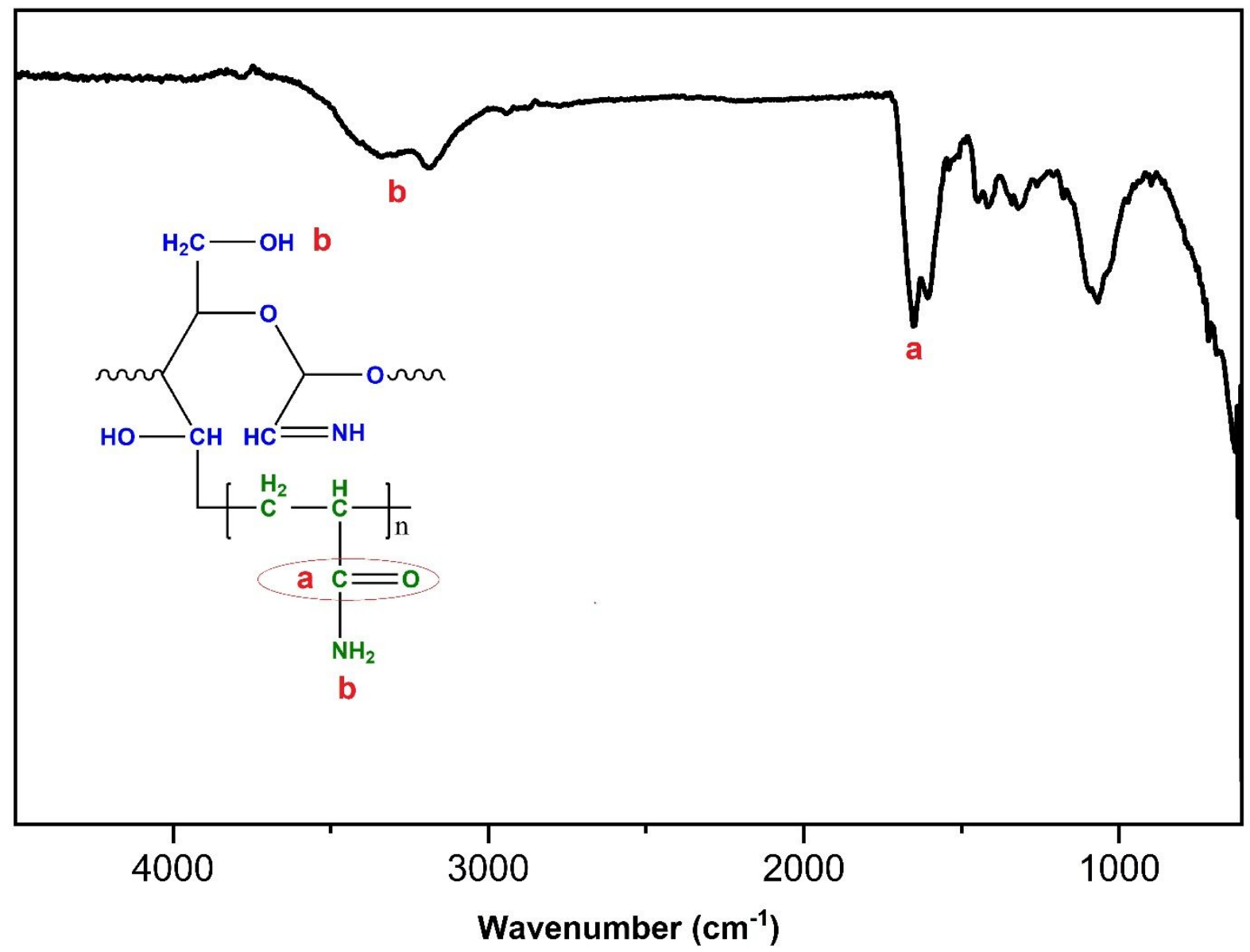

Figure S1. The FT-IR Spectrum of chitosan-graft-polyacrylamide. 


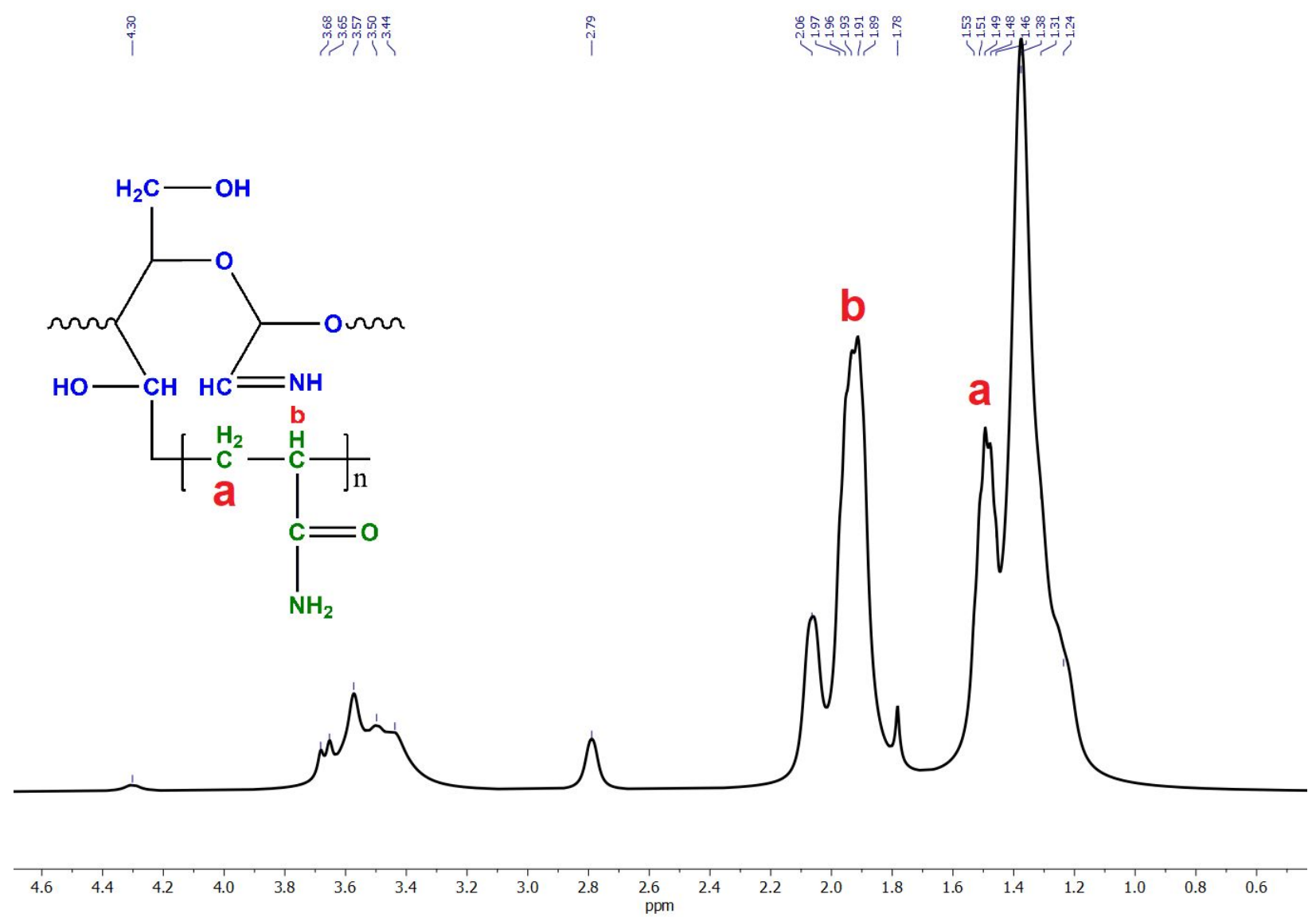

Figure S2. The ${ }^{1} \mathrm{H}$ NMR Spectrum of chitosan-graft-polyacrylamide. 